\title{
Can copeptin predict the severity of coronavirus disease 2019 infection?
}

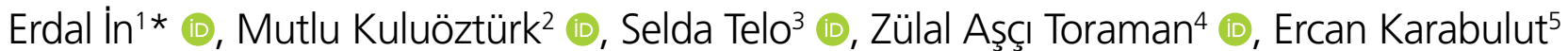

\section{SUMMARY}

OBJETIVE: Coronavirus disease 2019 (COVID-19) has quickly turned into a health problem globally. Early and effective predictors of disease severity are needed to improve the management of the patients affected with COVID-19. Copeptin, a 39-amino acid glycopeptide, is known as a C-terminal unit of the precursor pre-provasopressin (pre-proAVP). Activation of AVP system stimulates copeptin secretion in equimolar amounts with AVP. This study aimed to determine serum copeptin levels in the patients with COVID-19 and to examine the relationship between serum copeptin levels and the severity of the disease.

METHODS: The study included 90 patients with COVID-19. The patients with COVID-19 were divided into two groups according to disease severity as mild/moderate disease $(n=35)$ and severe disease $(n=55)$. All basic demographic and clinical data of the patients were recorded and blood samples were collected.

RESULTS: Copeptin levels were significantly higher in the patients with severe COVID-19 compared with the patients with mild/moderate COVID-19 ( $p<0.001)$. Copeptin levels were correlated with ferritin and fibrinogen levels positively $(r=0.32, p=0.002$ and $r=0.25, p=0.019$, respectively), and correlated with oxygen saturation negatively $(r=-0.37, p<0.001)$. In the multivariate logistic regression analysis, it was revealed that copeptin (OR: 2.647, 95\% CI 1.272-5.510; $p=0.009$ ) was an independent predictor of severe COVID-19 disease. A cutoff value of $7.84 \mathrm{ng} /$ $\mathrm{mL}$ for copeptin predicted severe COVID-19 with a sensitivity of $78 \%$ and a specificity of $80 \%$ (AUC: $0.869,95 \% \mathrm{Cl} 0.797-0.940 ; \mathrm{p}<0.001$ ). CONCLUSION: Copeptin could be used as a favorable prognostic biomarker while determining the disease severity in COVID-19. KEYWORDS: COVID-19. Mild/Moderate COVID-19. Severe COVID-19. Copeptin. Biomarkers.

\section{INTRODUCTION}

In the city of Wuhan in China, a pneumonia outbreak that developed due to a novel coronavirus was detected in December 2019. The outbreak could not be taken under control and it spread all around the world, resulting in a pandemic. The novel coronavirus was defined as severe acute respiratory syndrome coronavirus 2 (SARS-CoV-2). Accordingly, the disease that resulted from the virus was defined as coronavirus disease 2019 (COVID-19) by the World Health Organization ${ }^{1,2}$. As of May
24, 2021, approximately 167 million COVID-19 cases and more than 3.4 million deaths were reported all around the world ${ }^{3}$.

Copeptin is a glycopeptide that consists of 39 amino acids. It is also related to arginine vasopressin (AVP). Copeptin is derived from the C-terminal part of pre-proAVP, which is an AVP precursor molecule. Together with AVP, copeptin is expressed from neurohypophysis simultaneously either with osmotic or hemodynamic signals. Therefore, it strongly correlates with plasma levels. AVP is

\footnotetext{
'Malatya Turgut Ozal University, Faculty of Medicine, Department of Chest Diseases - Malatya, Turkey.

${ }^{2}$ Firat University, Faculty of Medicine, Department of Chest Diseases - Elazig, Turkey.

${ }^{3}$ Firat University, Faculty of Dentistry, Department of Biochemistry - Elazig, Turkey.

${ }^{4}$ FIrat University, Faculty of Medicine, Department of Medical Microbiology - Elazig, Turkey.

${ }^{5}$ Ankara Yildirim Beyazit Üniversity, Faculty of Medicine, Department of Medical Pharmacology - Ankara, Turkey.

*Corresponding author: inerda@gmail.com

Conflicts of interest: the authors declare there is no conflicts of interest. Funding: none.

Received on June 03, 2021. Accepted on June 18, 2021.
} 
a hormone with antidiuretic and vasoconstrictive qualities. Accordingly, it exhibits endogenous stress responses and stimuli, such as hypotension, hypoxia, hyperosmolarity, acidosis, and infections increase its expression. Nevertheless, it cannot be used as a biomarker due to circadian rhythm, short half-life, and unstable molecule status of AVP. On the other hand, copeptin is a peptin that is more stable and its levels can be detected in blood easily ${ }^{4-6}$.

In previous studies, it was demonstrated that levels of serum copeptin were increased in diseases, such as community-acquired pneumonia (CAP), ventilator-associated pneumonia (VAP), lower respiratory tract infections, acute exacerbation of chronic obstructive pulmonary disease (COPD), and sepsis, and these increases were related to poor prognosis ${ }^{7-12}$.

It is suggested that the assessment and management of COVID-19 should be conducted according to the disease severity. In terms of the initial data that were obtained from China, it was observed that $81 \%$ of the patients with COVID19 experienced mild or moderate diseases, which were similar to cold and mild pneumonia, whereas $14 \%$ of the patients had severe diseases in addition to $5 \%$ of the patients, who had critical and fatal diseases ${ }^{13}$. At this point, early recognition of severe forms of the disease is vital for early hospitalization and appropriate treatment of the patients. The clinical status, oxygen saturation, and comorbidity mainly determine the need for hospitalization, while certain laboratory parameters can also facilitate the assessment of the severity of the disease ${ }^{14}$. In various studies, it was demonstrated that biomarkers, such as CRP (C-reactive protein), D-dimer, ferritin, cardiac troponin, interleukin-6 (IL-6), and lymphocyte counts, could be used in estimating the severity of the disease in risk classification $^{15}$. In a very recent study, copeptin was found to be a useful biomarker in distinguishing COVID-19-associated pneumonia from $\mathrm{CAP}^{16}$. However, in the literature, it was observed that no study evaluated the relationship between COVID-19 severity and copeptin.

In this study, it was aimed to measure the serum copeptin levels in the patients with COVID-19, to evaluate the relationship of serum copeptin levels with disease severity, and to evaluate the relationships between copeptin and certain inflammatory parameters.

\section{METHODS}

\section{Study subjects}

In this study, 90 consecutive patients with COVID-19 diagnosis, who were admitted to the Pandemic Clinic in the Faculty of Medicine at Firat University between August and October
2020, were included in the sample according to the inclusion criteria. Patients older than 18 years were included in the study.

COVID-19 diagnosis was defined as a SARS-CoV-2 positive real-time reverse-transcriptase polymerase chain reaction (RT-PCR) from a nasal and/or throat swab together with signs, symptoms, or radiological that suggest COVID-19 infection. In the study, the clinical parameters were recorded as well as the demographic data. Following the investigation of the histories and physical examinations of the subjects, the blood samples were drawn from the patients before the treatment process.

Upon admission to the hospital, the patients with COVID-19 were categorized into three groups by considering the clinical findings, respiratory rates, oxygen saturation $\left(\mathrm{SpO}_{2}\right)$ levels, and low-dose chest CT findings ${ }^{17}$. The details of the classification are as follows:

Mild illness: mild clinical symptoms, no sign of pneumonia on low-dose CT.

Moderate illness: mild respiratory symptoms, positive signs of pneumonia on low-dose $\mathrm{CT}$, and $\mathrm{SpO}_{2} \geq 94 \%$ on room air.

Severe illness: Those who meet any of the following criteria:

1. Respiratory rate $>30$ times per $\mathrm{min}$;

2. $\mathrm{SpO}_{2}<94 \%$ at room air;

3. Lung infiltrates $>50 \%$ on low-dose CT.

In the study, the exclusion criteria covered the patients who had heart failure, renal failure, COPD, acute myocardial infarction, acute coronary syndrome, interstitial lung disease, any organ malignancy, or immunosuppression (HIV infection, solid organ or stem cell transplantation, or any immunosuppressive treatment). Additionally, pregnancy was an exclusion criterion in the study.

\section{Ethics approval}

The study was conducted within the framework of the Helsinki Declaration. The study was also approved by the Ethical Committee of the Medicine Faculty of Firat University (issue: $402252 / 20,07,2020)$. The subjects who participated in the study also provided their written consent to be included in the study.

\section{Measurement of serum copeptin levels}

In the measurements, the separation of the serum was conducted by centrifuging the samples at $4,000 \mathrm{~g}$ for $10 \mathrm{~min}$. Then the samples were frozen at $-80^{\circ} \mathrm{C}$ for further analysis. A double-antibody sandwich enzyme-linked immunosorbent assay kit (Catalog No. 201-12-5463 Human copeptin Elisa Kit: Sunred Biological Technology Co. Ltd. Shanghai) was used to measure the serum copeptin levels. The assay had a sensitivity of $0.067 \mathrm{ng} / \mathrm{mL}$. The inter-assay and intra-assay calculation values were $<12 \%$ and $<10 \%$, respectively. Furthermore, the detection range of copeptin was $0.07-20 \mathrm{ng} / \mathrm{mL}$. 


\section{Statistical analyses}

In the statistical analyses, IBM SPSS Statistics 21 (Version 21, authorization code: d91314f638c364094170, Armonk, NY, USA) software was used. The results obtained in the analyses were stated as mean $\pm S D$. The level of statistical significance was regarded as $\mathrm{p}<0.05$. To compare two independent samples, the student's t-test was conducted. To compare the distribution of sex between the groups, Chi-square $\left(\chi^{2}\right)$ test was conducted. The parametric variables were evaluated by the Pearson correlation analysis. In the study, univariate and multivariate analyses were conducted by binary logistic regression to evaluate the variables that could predict severe COVID-19 disease. In the analysis, a 95\% confidence interval (CI) was adopted while calculating the odds ratios (ORs). The receiver operating characteristic (ROC) analysis method was to determine the cutoff value for copeptin. With the ROC curve, the area under curve (AUC) value was determined.

\section{RESULTS}

\section{Comparison of groups}

In the study population, 35 patients were assigned to a mild/ moderate disease and 55 patients were allocated to a severe disease. The mean serum copeptin levels of the patients with mild/ moderate and severe COVID-19 were $6.4 \pm 2.2$ and $11.7 \pm 4.6 \mathrm{ng} /$ $\mathrm{mL}$, respectively $(\mathrm{p}<0.001)$. Comparison of all laboratory data of the patients with COVID-19 was demonstrated in Table 1.

\section{Correlation analysis}

In the analyses, it was observed that serum copeptin levels positively correlated with serum ferritin and fibrinogen levels $(r=0.32$, $\mathrm{p}=0.002$ and $\mathrm{r}=0.25, \mathrm{p}=0.019$, respectively), whereas negatively correlating with $\mathrm{SaO}_{2}$ levels $(\mathrm{r}=-0.37$, $\mathrm{p}<0.001$; Figure 1).
Table 1. Comparison of the demographical and laboratory data of two groups of patients with COVID-19.

\begin{tabular}{|c|c|c|c|}
\hline & $\begin{array}{c}\text { Mild/ } \\
\text { moderate } \\
\text { disease } \\
(\mathrm{n}=35)\end{array}$ & $\begin{array}{l}\text { Severe } \\
\text { disease } \\
(\mathrm{n}=55)\end{array}$ & $\mathrm{p}$ \\
\hline Age, years & $44.5 \pm 14.9$ & $58.8 \pm 16.8$ & $<0.001$ \\
\hline Sex, male, n(\%) & $18(51.4)$ & $35(63.6)$ & 0.25 \\
\hline $\mathrm{SaO}_{2}, \%$ & $94.7 \pm 2.5$ & $88.4 \pm 4.4$ & $<0.001$ \\
\hline \multicolumn{4}{|c|}{ Complete blood count } \\
\hline Leukocyte, $\times 10^{9} / \mathrm{L}$ & $6.4 \pm 2.8$ & $6.0 \pm 3.2$ & 0.53 \\
\hline Hemoglobin, g/dL & $13.5 \pm 1.9$ & $13.6 \pm 2.0$ & 0.87 \\
\hline Platelet, $\times 10^{9} / \mathrm{L}$ & $194.5 \pm 40.7$ & $179.8 \pm 83.1$ & .33 \\
\hline \multicolumn{4}{|l|}{ Biochemical markers } \\
\hline Urea, mg/dL & $32.7 \pm 12.7$ & $39.8 \pm 16.2$ & 0.03 \\
\hline Creatinine, $\mathrm{mg} / \mathrm{dL}$ & $0.81 \pm 0.23$ & $0.89 \pm 0.25$ & 0.13 \\
\hline ALT, U/L & $22.1 \pm 10.8$ & $32.9 \pm 20.1$ & 0.004 \\
\hline $\mathrm{AST}, \mathrm{U} / \mathrm{L}$ & $27.0 \pm 15.8$ & $40.7 \pm 20.2$ & 0.001 \\
\hline $\mathrm{LDH}, \mathrm{U} / \mathrm{L}$ & $262.9 \pm 73.2$ & $344.7 \pm 137.8$ & 0.002 \\
\hline D-dimer, mg/L & $0.8 \pm 1.1$ & $1.2 \pm 1.8$ & 0.24 \\
\hline \multicolumn{4}{|c|}{ Inflammatory markers } \\
\hline CRP, mg/L & $23.8 \pm 40.6$ & $84.6 \pm 64.2$ & $<0.001$ \\
\hline Procalcitonin, mg/L & $0.34 \pm 0.5$ & $0.30 \pm 0.41$ & 0.61 \\
\hline Ferritin, ng/mL & $185.2 \pm 198.0$ & $601.9 \pm 364.4$ & $<0.001$ \\
\hline Fibrinogen, $\mathrm{mg} / \mathrm{dL}$ & $402.7 \pm 128.7$ & $536.8 \pm 159.9$ & $<0.001$ \\
\hline \multicolumn{4}{|l|}{ Cardiac markers } \\
\hline CK, U/L & $84.6 \pm 121.3$ & $162.5 \pm 184.6$ & 0.03 \\
\hline CK-MB， U/L & $20.9 \pm 19.5$ & $31.2 \pm 32.4$ & 0.09 \\
\hline Troponin I, $\mu \mathrm{g} / \mathrm{L}$ & $0.02 \pm 0.1$ & $0.13 \pm 0.8$ & 0.46 \\
\hline Copeptin, ng/mL & $6.4 \pm 2.2$ & $11.7 \pm 4.6$ & $<0.001$ \\
\hline
\end{tabular}

$\mathrm{SaO}_{2}$ : oxygen saturation; ALT: alanine transaminase; AST: aspartate transaminase; LDH: lactate dehydrogenase; CRP: C-reactive protein; CK: creatine kinase. Bold values are statistically significant values $(p<0.05)$.

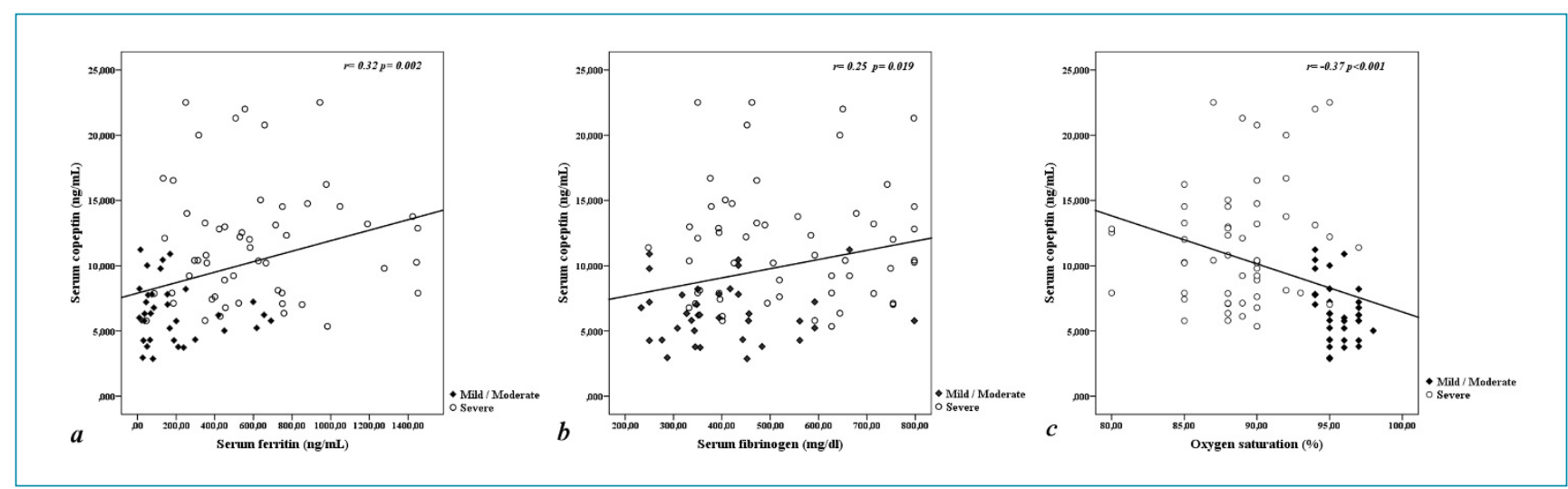

Figure 1. Correlation between serum copeptin levels and (a) ferritin, (b) fibrinogen, and (c) oxygen saturation levels in patients with COVID-19. 


\section{Logistic regression analysis}

The univariable logistic regression model demonstrated the following parameters that were statistically significant, which included age, copeptin, CRP, fibrinogen, AST, ALT, LDH, and ferritin. In the multivariable logistic regression model, it was observed that that older age (OR: 1.139, 95\%CI 1.036-1.251; $\mathrm{p}=0.007$ ) and increased copeptin (OR: 2.647, 95\%CI 1.272-5.510; $\mathrm{p}=0.009$ ) and ferritin (OR: 1.005, 95\%CI 1.000-1.010; $\mathrm{p}=0.034$ ) levels were independent predictors of severe COVID-19 disease (Table 2).

\section{ROC curve analysis}

The efficacy of biochemical and inflammatory markers for the prediction of severe disease was evaluated by ROC analysis. AUC of copeptin, ferritin, CRP, fibrinogen, AST, LDH, and CK were found as 0.869 (95\%CI 0.797-0.940; $<<0.001), 0.846(95 \% \mathrm{CI}$ 0.765-0.928; $<<0.001), 0.826(95 \%$ CI 0.734-0.918; $<<0.001)$,

Table 2. Results of binary logistic regression analysis of potential predictors of severe COVID-19 disease.

\begin{tabular}{|c|c|c|c|c|}
\hline & \multicolumn{2}{|c|}{ Univariable model } & \multicolumn{2}{|c|}{ Multivariable model } \\
\hline & $p$ & $\begin{array}{c}\text { OR } \\
(95 \% \mathrm{Cl})\end{array}$ & $p$ & $\begin{array}{c}\text { OR } \\
(95 \% \mathrm{Cl})\end{array}$ \\
\hline Age, years & $<0.001$ & $\begin{array}{c}1.055 \\
(1.024-1.086) \\
\end{array}$ & 0.007 & $\begin{array}{c}1.139 \\
(1.036-1.251) \\
\end{array}$ \\
\hline Sex, male & 0.25 & $\begin{array}{c}1.653 \\
(0.699-3.909)\end{array}$ & & \\
\hline $\begin{array}{l}\text { Copeptin, } \\
\mathrm{ng} / \mathrm{mL}\end{array}$ & $<0.001$ & $\begin{array}{c}1.740 \\
(1.362-2.223)\end{array}$ & 0.009 & $\begin{array}{c}2.647 \\
(1.272-5.510)\end{array}$ \\
\hline CRP, mg/L & $<0.001$ & $\begin{array}{c}1.033 \\
(1.017-1.050)\end{array}$ & & \\
\hline $\begin{array}{l}\text { Urea, } \mathrm{mg} / \\
\mathrm{dL}\end{array}$ & 0.57 & $\begin{array}{c}1.005 \\
(0.988-1.022)\end{array}$ & & \\
\hline $\begin{array}{l}\text { Fibrinogen, } \\
\mathrm{mg} / \mathrm{dL}\end{array}$ & $<0.001$ & $\begin{array}{c}1.006 \\
(1.003-1.010)\end{array}$ & & \\
\hline AST, U/L & 0.003 & $\begin{array}{c}1.054 \\
(1.018-1.091) \\
\end{array}$ & & \\
\hline ALT, U/L & 0.008 & $\begin{array}{c}1.048 \\
(1.012-1.084)\end{array}$ & & \\
\hline $\mathrm{LDH}, \mathrm{U} / \mathrm{L}$ & 0.005 & $\begin{array}{c}1.008 \\
(1.002-1.013)\end{array}$ & & \\
\hline $\begin{array}{l}\text { Ferritin, } \\
\mathrm{ng} / \mathrm{mL}\end{array}$ & $<0.001$ & $\begin{array}{c}1.006 \\
(1.003-1.009)\end{array}$ & 0.034 & $\begin{array}{c}1.005 \\
(1.000-1.010)\end{array}$ \\
\hline $\mathrm{CK}, \mathrm{U} / \mathrm{L}$ & 0.06 & $\begin{array}{c}1.005 \\
(1.000-1.011)\end{array}$ & & \\
\hline $\begin{array}{l}\text { Troponin, } \\
\mu \mathrm{g} / \mathrm{L}\end{array}$ & 0.59 & $\begin{array}{c}1.616 \\
(0.288-9.075)\end{array}$ & & \\
\hline
\end{tabular}

CRP: C-reactive protein; AST: aspartate transaminase; ALT: alanine transaminase; LDH: lactate dehydrogenase; CK: creatine kinase.
0.743 (95\%CI 0.639-0.847; $\mathrm{p}<0.001), 0.740$ (95\%CI 0.635$0.845 ; \mathrm{p}<0.001), 0.676$ (95\%CI 0.563-0.789; $\mathrm{p}=0.005)$, and 0.698 (95\%CI 0.590-0.807; $\mathrm{p}=0.002$ ), respectively. Among these parameters, copeptin occupied the maximum area with 0.869 . When the cutoff value for copeptin in predicting of severe disease was determined to be 7.84 , the sensitivity was determined as $78 \%$, whereas the specificity was $80 \%$.

\section{DISCUSSION}

Biomarkers that predict the outcomes of diseases, should be higher in the disease groups compared with the healthy groups and should reflect the severity of the disease. The significance of copeptin in the patients with COVID-19 and its role as a biomarker in predicting disease severity are unknown. Our study is the first one to evaluate the relationship between severity of COVID-19 and copeptin and striking results were obtained in our study. It was determined that copeptin levels of the patients with severe COVID-19 were significantly higher than the patients with mild/moderate COVID-19, and this increase was correlated with disease severity.

It was demonstrated that copeptin played active roles in lung diseases, such as pneumonia, and it was superior to traditional inflammatory markers as a prognostic marker in the patients with $\mathrm{CAP}^{5,18}$. The levels of copeptin in the patients with COVID-19 could be increased due to hemodynamic, osmotic, or inflammatory reasons. In the patients with pneumonia, it was discovered that the levels of copeptin were elevated as the severity of sepsis was elevated ${ }^{12}$. Similarly, as the severity of the disease increases in the patients with COVID-19, the expression of copeptin, simultaneously with AVP, from neurohypophysis could be increased with hemodynamic and osmotic signals due to changes in blood pressure and plasma osmolality. Furthermore, it was reported that the endotoxins and inflammatory markers, which increased during respiratory infections, stimulated AVP secretion ${ }^{4,6}$. In our study, it was determined that inflammatory markers, such as CRP, ferritin, and fibrinogen, were elevated in the patients with severe COVID-19, whereas positive correlations were discovered between serum copeptin levels, serum ferritin, and fibrinogen levels. As the severity of the disease was increased, it was believed that the inflammatory markers and cytokines contributed to the increase in copeptin levels. Additionally, it is known that the gas exchange in the lungs during lower respiratory tract infections results in changes in the AVP system. AVP expression could be induced by certain factors such as acidosis, pain, hypoxia, or neuroendocrine stress as well ${ }^{6}$. In the patients with severe COVID-19, it is known that oxygen levels are lower and the stress responses are higher. Conditions such as hypoxia and pain, which develop as the 
severity of pneumonia increases, could contribute to copeptin expression. In the current study, it was discovered that the saturation levels were lower in severe patients and saturation levels and copeptin levels were strongly correlated.

Up to date, the prognostic value of copeptin in CAP patients was investigated in several studies in the literature. Masiá et al. ${ }^{10}$ evaluated $174 \mathrm{CAP}$ patients and reported that copeptin was an independent marker of mortality. In the current study, it was determined that copeptin yielded high diagnostic accuracy in predicting mortality when the cutoff value was regarded as $>18.9 \mathrm{pmol} / \mathrm{L}$ (sensitivity: $71.4 \%$, specificity: 79.5\%). Similarly, Kolditz et al. ${ }^{19}$ evaluated 51 CAP patients and investigated copeptin's diagnostic value in predicting admission to the intensive care unit 7 days from hospitalization and predicting mortality by using ROC analysis. In this study, it was determined that copeptin had $78 \%$ sensitivity and $79 \%$ specificity when the cutoff value was regarded as $35 \mathrm{pmol} / \mathrm{L}$. In our study, it was observed that copeptin had $78 \%$ sensitivity and $80 \%$ specificity in terms of distinguishing the patients with severe COVID-19 from those patients with mild/moderate when the optimal cutoff value was regarded as $7.84 \mathrm{ng} / \mathrm{mL}$. According to the findings of our study, copeptin had a higher predictive value in predicting severe disease compared with biochemical and inflammatory markers such as CRP, ferritin, fibrinogen, and LDH used routinely. Furthermore, copeptin was found to be an independent predictor of severe COVID19 disease in the multivariable logistic regression analysis. Considering the findings of our study, copeptin can be a simple and useful marker for predicting the severity of COVID-19 with high sensitivity and specificity while yielding rapid results. Nevertheless, our study is a first on this subject, and a series of studies are required to support these results.

In conclusion, in this study, it was determined that serum copeptin levels were higher in the patients with severe COVID19 compared with the patients with mild/moderate COVID-19 and related to disease severity. Moreover, multivariable logistic regression analysis identified copeptin as an independent predictor for COVID-19 severity. Therefore, copeptin could be a useful and prognostic biomarker that can be used in the patients with distinguishing severe COVID-19 from the patients with mild/moderate COVID-19.

\section{AUTHORS" CONTRIBUTIONS}

İE: Conceptualization, Data curation, Formal analysis, Methodology, Investigation, Resources, Writing - original draft, Writing - review \& editing. KM: Conceptualization, Methodology, Investigation, Methodology, Resources. TS: Methodology, Data Curation, Formal analysis, Investigation, Resources. ATZ: Methodology, Data Curation, Investigation, Supervision, Writing - review \& editing. KE: Formal analysis, Supervision, Writing - review \& editing. All authors read and approved the final manuscript.

\section{AVAILABILITY OF DATA}

The data that support the findings of this study are available from the corresponding author on reasonable request.

\section{REFERENCES}

1. Vieira JM, Ricardo OMP, Hannas CM, Kanadani TCM, Prata TDS, Kanadani FN. What do we know about COVID-19? A review article. Rev Assoc Med Bras (1992). 2020;66(4):53440. https://doi.org/10.1590/1806-9282.66.4.534

2. World Health Organization. Naming the coronavirus disease (COVID-19) and the virus that causes it [cited on May 24, 2021]. Available from: https://www.who.int/emergencies/ diseases/novel-coronavirus-2019/technical-guidance/namingthe-coronavirus-disease-(covid-2019)-and-the-virus-thatcauses-it\#: :text=Official\%20names\%20have \%20been \%20 announced, \%2DCoV\%2D2).

3. Cornavirus Resource Center. Global map. COVID-19 Dashboard by the Center for Systems Science and Engineering (CSSE) at Johns Hopkins University (JHU). Johns Hopkins University \& Medicine [cited on May 24, 2021]. Available from: https:// coronavirus.jhu.edu/map.html

4. Christ-Crain M, Fenske W. Copeptin in the diagnosis of vasopressin-dependent disorders of fluid homeostasis. Nat Rev Endocrinol. 2016;12(3):168-76. https://doi.org/10.1038/ nrendo.2015.224
5. Katan M, Morgenthaler N, Widmer I, Puder JJ, König C, Müller B, et al. Copeptin, a stable peptide derived from the vasopressin precursor, correlates with the individual stress level. Neuro Endocrinol Lett. 2008;29(3):341-6. PMID: 18580851

6. Dobsa L, Edozien KC. Copeptin and its potential role in diagnosis and prognosis of various diseases. Biochem Med (Zagreb). 2013;23(2):172-90. https://doi.org/10.11613/bm.2013.021

7. Stolz D, Christ-Crain M, Morgenthaler NG, Leuppi J, Miedinger $D$, Bingisser R, et al. Copeptin, C-reactive protein, and procalcitonin as prognostic biomarkers in acute exacerbation of COPD. Chest. 2007;131(4):1058-67. https://doi.org/10.1378/ chest.06-2336

8. Müller B, Morgenthaler N, Stolz D, Schuetz P, Müller C, Bingisser $\mathrm{R}$, et al. Circulating levels of copeptin, a novel biomarker, in lower respiratory tract infections. Eur J Clin Invest. 2007;37(2):145-52. https://doi.org/10.1111/j.13652362.2007.01762.x

9. Krüger S, Papassotiriou J, Marre R, Richter K, Schumann C, von Baum $\mathrm{H}$, et al. Pro-atrial natriuretic peptide and pro-vasopressin to predict severity and prognosis in community-acquired 
pneumonia: results from the German competence network CAPNETZ. Intensive Care Med. 2007;33(12):2069-78. https:// doi.org/10.1007/s00134-007-0895-5

10. Masiá M, Papassotiriou J, Morgenthaler NG, Hernández I, Shum C, Gutiérrez F. Midregional pro-A-type natriuretic peptide and carboxy-terminal provasopressin may predict prognosis in community-acquired pneumonia. Clin Chem. 2007;53(12):2193201. https://doi.org/10.1373/clinchem.2007.085688

11. Jochberger S, Dörler J, Luckner G, Mayr VD, Wenzel V, Ulmer $\mathrm{H}$, et al. The vasopressin and copeptin response to infection, severe sepsis, and septic shock. Crit Care Med. 2009;37(2):47682. https://doi.org/10.1097/CCM.0b013e3181957532

12. Seligman R, Papassotiriou J, Morgenthaler NG, Meisner $M$, Teixeira PJZ. Copeptin, a novel prognostic biomarker in ventilator-associated pneumonia. Crit Care. 2008;12(1):R11. https://doi.org/10.1186/cc6780

13. Wu Z, McGoogan JM. Characteristics of and important lessons from the coronavirus disease 2019 (COVID-19) outbreak in China: summary of a report of 72314 cases from the Chinese Center for Disease Control and Prevention. JAMA. 2020;323(13):1239-42. https://doi.org/10.1001/ jama.2020.2648
14. Gandhi RT, Lynch JB, Del Rio C. Mild or moderate COVID-19. N Engl J Med. 2020;383(18):1757-66. https://doi.org/10.1056/ NEJMcp2009249

15. Velavan TP, Meyer CG. Mild versus severe COVID-19: laboratory markers. Int J Infect Dis. 2020;95:304-7. https:// doi.org/10.1016/j.ijid.2020.04.061

16. Kuluöztürk M, İn E, Telo S, Karabulut E, Geçkil AA. Efficacy of copeptin in distinguishing COVID-19 pneumonia from community-acquired pneumonia. J Med Virol. 2021;93(5):311321. https://doi.org/10.1002/jmv.26870

17. National Institute of Health. Coronavirus disease 2019 (COVID19) treatment guidelines [cited on Dec 17, 2020]. Available from: https://www.covid19treatmentguidelines.nih.gov/

18. Katan M, Müller B, Christ-Crain M. Copeptin: a new and promising diagnostic and prognostic marker. Crit Care. 2008;12(2):117. https://doi.org/10.1186/cc6799

19. Kolditz M, Halank M, Schulte-Hubbert B, Bergmann S, Albrecht S, Höffken G. Copeptin predicts clinical deterioration and persistent instability in community-acquired pneumonia. Respir Med. 2012;106(9):1320-8. https://doi.org/10.1016/j. rmed.2012.06.008 